\title{
ARQUEOLOGÍA DE RESCATE EN EL PATIO HISTÓRICO DE LA FACULTAD DE HUMANIDADES Y ARTES, UNIVERSIDAD NACIONAL DE ROSARIO. TEMPORADA 2019
}

\author{
Redactoras del Informe: Mónica Valentini ${ }^{1}$ y Diana S. Tamburini ${ }^{2}$
}

\begin{abstract}
Participantes por el Departamento de Arqueología: Mónica Valentini, Diana S. Tamburini, Mariana Algraín, Irene Dosztal, Fernando Oliva, Alejandro Farrugia, Guido Scaglione, Gabriel Spinetta Cadirola, Ingrid Cabrol, Franco Abatángelo, Liliana Leiva, Mauro Tonello, Natalia Cisneros, Silvina Codina y Gustavo Fernetti.
\end{abstract}

\section{Introducción}

En este Anexo se presenta el segundo informe de las tareas de monitoreo y rescate arqueológico llevadas a cabo en el patio histórico de la Facultad de Humanidades y Artes (en adelante FHyA), Universidad Nacional de Rosario. Desde el inicio del hundimiento de un sector del patio en octubre de 2018, la Facultad inició el recambio de los desagües ubicados allí. A partir de ese momento se realizó durante el 2019 una reestructuración del patio con cambio completo de piso, renovación de pluviales y optimización de su uso para recreación. Esto incluyó el retiro del mástil ubicado en el sector oeste del patio (Figuras 1 y 2), así como también la recuperación de un sector de galería donde se encontraba la Escuela de Historia. La investigación arqueológica llevada hasta el momento del presente informe indica cuatro sectores reconocidos a partir de las excavaciones realizadas y de acuerdo con el seguimiento de la obra de restauración del predio.

\section{Actividades desarrolladas}

El trabajo previo relacionado con el rescate arqueológico incluye una serie de monitoreos y el rescate arqueológico durante el año 2018, que significaron la recuperación de materiales encontrados en el relleno de sedimento y en los caños de desagües que se levantaron y cambiaron en la obra. Los materiales recolectados constan de restos de materiales del siglo XIX y principios del siglo XX, como fragmentos de vidrio,

1 Departamento de Arqueología, Escuela de Antropología, Facultad de Humanidades y Artes, Universidad Nacional de Rosario. E-mail: mopavalentini@gmail.com

2 Departamento de Arqueología, Escuela de Antropología, Facultad de Humanidades y Artes, Universidad Nacional de Rosario. E-mail: dianatamburini@hotmail.com

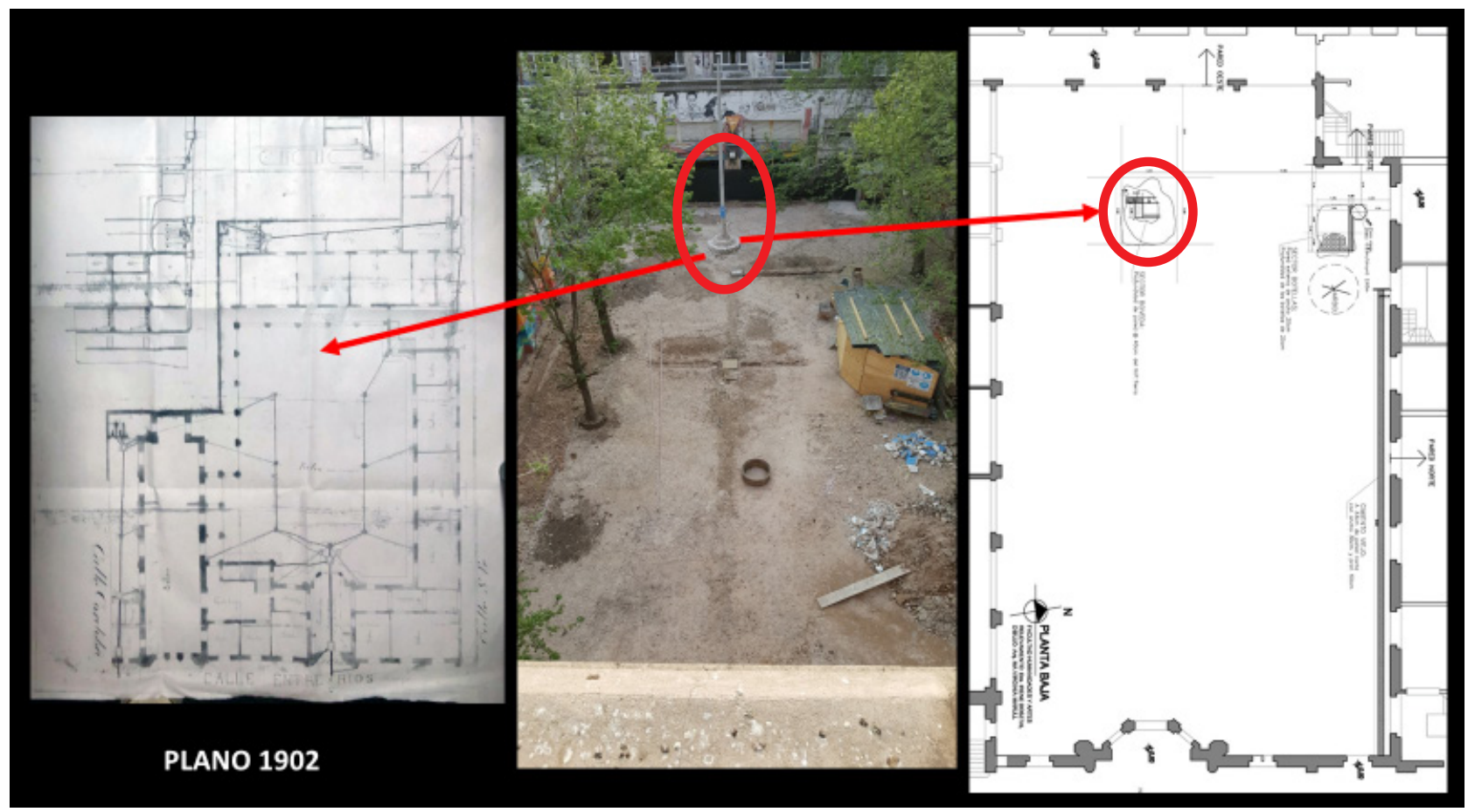

Figura 1. (Izq.) Plano FHyA 1902. (Centro) Ubicación del mástil 2019. (Der.) Planta con la ubicación de la bóveda existente debajo del mástil. 

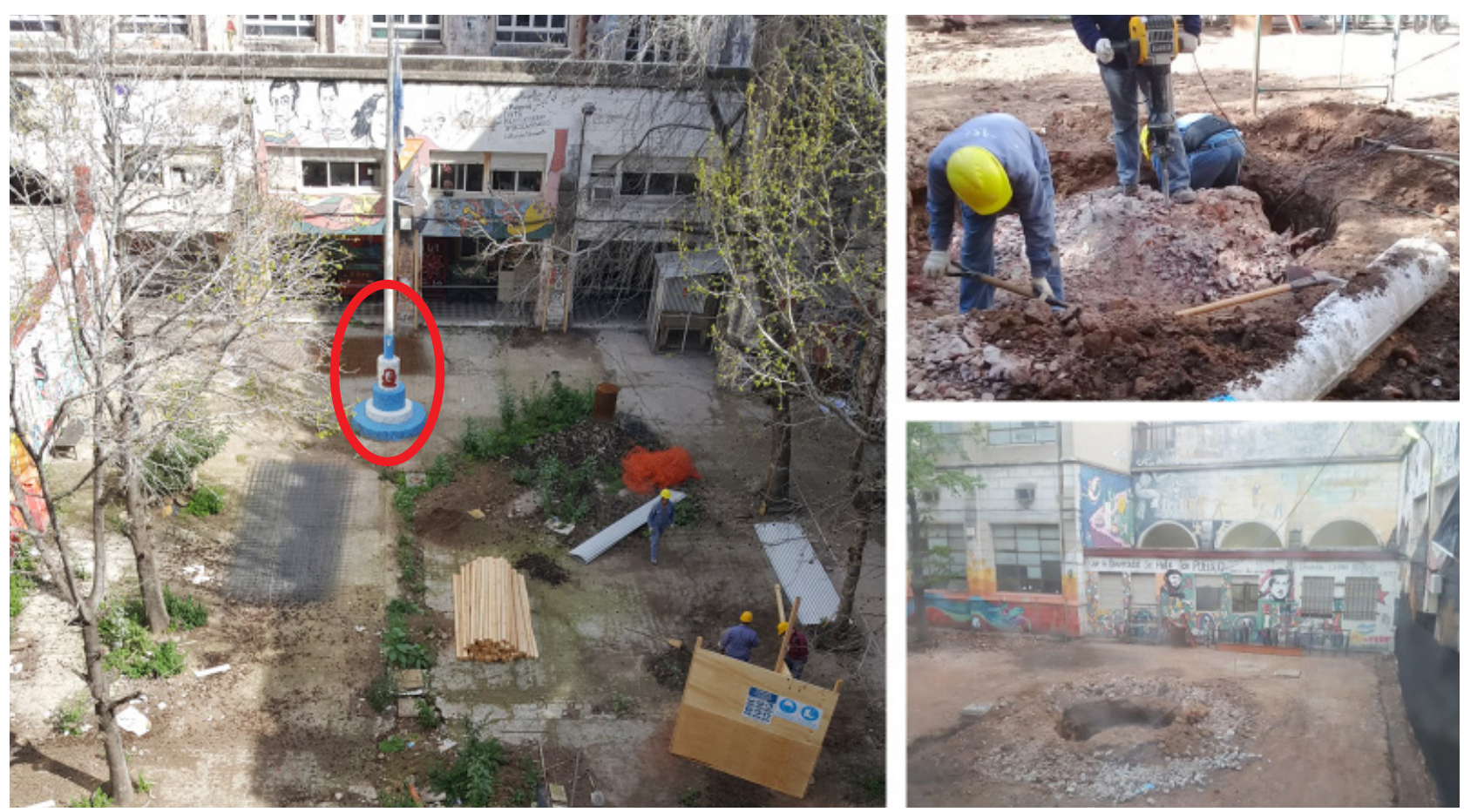

Figura 2. Vista desde el 2do. piso de la FHyA en dirección oeste previo retiro del mástil 2019.

gres cerámico, loza, vidrio y metal. Es posible que vinieran en el sedimento del relleno utilizado. Se trata de elementos que formaron parte del relleno efectuado en el anterior reemplazo de conductos de desagües. Junto a estos materiales, sorprende el hallazgo de pequeños y medianos fragmentos de cerámica prehispánica (Tamburini, et al., 2019). Algunos de estos fragmentos presentan un siglado particular y tal vez tengan relación con los depósitos de las colecciones arqueológicas que estaban en el Instituto de Antropología ${ }^{1}$ (ver González, 1959), producto de los materiales que se traían de las primeras excavaciones arqueológicas que los miembros del Instituto realizaban y que por diferentes razones que se están analizando terminaron en esos desagües.

Podemos enumerar una serie de técnicas y procedimientos empleados para el estudio arqueológico en base a los que desarrolló la arqueología urbana (Schávelzon, 1992, 2012, 2018) y particularmente un acompañamiento arqueológico de la obra edilicia (Camino, 2009). Para el estudio arqueológico y su interpretación se realizaron las siguientes actividades, tratando de cubrir un amplio espectro de información, aunque algunos resultados y actividades quedaron truncos con el inicio de la pandemia de Covid-19 y la respectiva cuarentena.

$>$ Relevamiento documental y Relevamiento fotográfico (fuentes primarias y secundarias)

- Programa de Preservación Documental. Escuela de Historia, FHyA, UNR.

- Archivo Torriglia, FHyA, UNR.

- Museo de la Ciudad, Rosario.

- Archivo Diario la Capital, Rosario.

- Colegio de la Santa Unión, hoy Virgen del Rosario (Ovidio Lagos y Salta, Rosario).
$>$ Relevamiento de información cartográfica y Catastral.

- Catastro Municipalidad de Rosario.

- Aguas Santafesinas.

- Obras privadas Municipalidad de Rosario.

- Registro de propiedad de Santa Fe.

$>$ Entrevistas a historiadores locales, no docentes de la Facultad y graduados para recabar información respecto de distintas transformaciones realizadas en el patio.

$>$ Fotografía aérea con drone (modelo DJI Mavic pro y DJI Phantom 4 Pro).

> Mapeo de los constructivos relevados arqueológicamente realizado por Irene Dosztal y estudiantes, y construcción del plano en AutoCad confeccionado por Arquitecta M.V. Marull.

$>$ Monitoreo permanente del avance de las obras civiles, hacia fin de año en el sector de la demolición de la Escuela de Historia para la recuperación de las antiguas galerías.

$>$ Registro de los materiales recolectados.

$>$ Relevamiento topográfico realizado por el Agrimensor Benito Vicioso de la Facultad de Ingeniería de la UNR, el cual acompaña este informe.

$>$ Evaluación de la acción de los procesos de formación de sitio en la estructuración del registro arqueológico del patio, considerando en particular los sesgos resultantes a lo largo del tiempo, así como aquellos que pueden afectar la preservación, representación y distribución espacial de 
los materiales arqueológicos.

$>$ Trabajo de gabinete que implica la limpieza, fotografía, acondicionamiento y el almacenamiento de los artefactos recuperados, según protocolos ya en uso.

$>$ Presentación de resultados preliminares (eventos científicos, publicaciones, medios gráficos, radiales, televisivos, público en general).

$>$ Se realizó una presentación fotográfica del trabajo en el VIII Simposio de Arqueología Histórica, los días 28 y 29 de noviembre de 2019, el cual se llevó a cabo en la facultad. La misma muestra se encuentra expuesta en la Sala De Reuniones del Consejo Directivo en el sexto piso del nuevo edificio de la FHyA (Valentini \& Tamburini,2019).

\section{Sectores identificados}

Estas tareas estuvieron destinadas a relevar y analizar las distintas estructuras que aparecieron en diferentes sectores del patio (Figuras 3 y 4). Las estructuras halladas nos han planteado varias opciones respecto de su objetivo al momento de construirlas:

Los sectores identificados son:
1) Sector bóveda

2) Sector contrapiso de botellas de gres cerámico o stoneware

3) Sector pozo ciego con corona de ladrillos

4) Estructuras de muros de momentos temporales distintos

1.- El sector de bóveda donde se retiró el mástil (Figura 5) está ubicado en la parte central del patio a $11,55 \mathrm{~m}$ de la pared norte y a $5 \mathrm{~m}$ de la pared este del mismo, las dimensiones en planta de esta área de intervención tienen unos 3,60 m en dirección E-W y unos 3 m en dirección N-S. Dentro de esta área se describen los siguientes muros:

a) un muro de $30 \mathrm{~cm}$ de espesor ubicado hacia el oeste del área, y que se extiende en la dirección N-S en toda la zona excavada (con la letra A en el plano anexo). Este muro tiene una profundidad de $40 \mathrm{~cm}$.

b) un muro de espesor de $30 \mathrm{~cm}$ con dirección E-W y con una longitud de $80 \mathrm{~cm}$ en esta misma dirección medida a partir de la cara este del muro del literal a).

c) en el extremo este de la cara norte del muro del literal b), se encontró el arranque de otro muro de espesor no relevado (se puede inferir de unos $15 \mathrm{~cm}$ ), que se desarrolla en la dirección N-S hasta el final de la zona excavada del área de intervención.

Este sector propone varias ideas, con el fin de descubrir la mayor superficie posible se realizó una excavación posicional

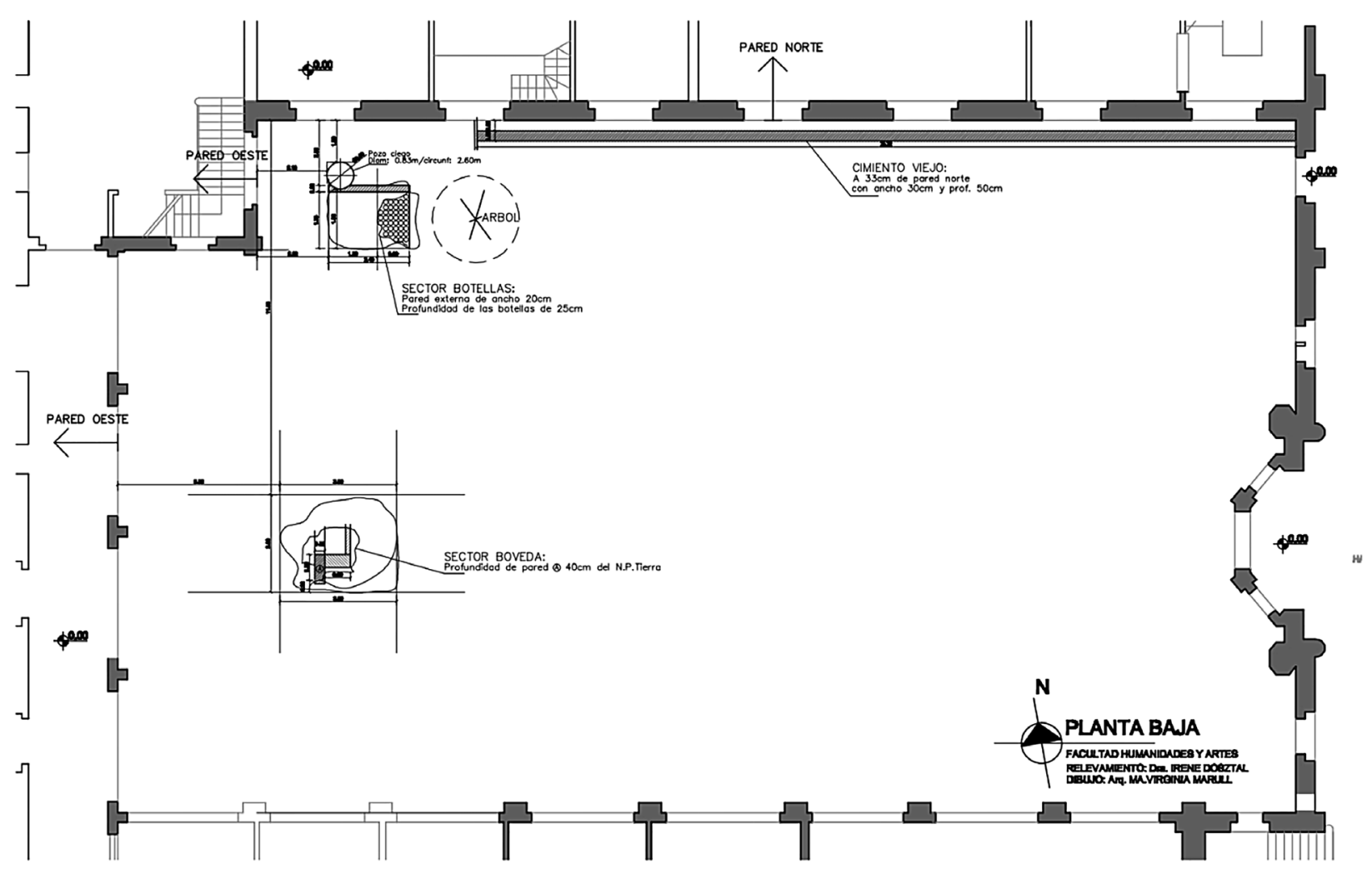

Figura 3. Plano con ubicación de los cuatro sectores identificados, elaborado por Dra. Irene Dosztal y Arquitecta María Virginia Marull. 
con la intención de descubrir la potencialidad del sector. Es posible que esta estructura se haya construido para proteger y permitir la existencia de albañales y cañerías por debajo de su nivel, y así asegurar su resultado debajo de solados sometidos a cargas importantes. Esto podría corresponder al momento de ocupación de la cervecería. Una segunda opción es que sirviera como estructura y cubierta bajo tierra de un espacio de almacenamiento. En este caso, también se la podría haber usado en tiempos de la cervecería. Los constructivos se presentaban no enteros, con un sector derrumbado y con una estructura diferenciada erigida por encima, por lo que es factible suponer que el sector fue rellenado para aplanar el terreno al momento de la construcción del patio del colegio.

2.- El sector de contrapiso de botellas de gres cerámico está ubicado en el rincón N-W del patio; esta porción está separada a unos 2,20 m de la pared oeste (es una sección del muro oeste lateral de la escalera interior) y a unos $2 \mathrm{~m}$ de la pared norte. Las dimensiones en planta de esta área de intervención tienen unos 2,50 m aproximadamente en dirección E-W y unos $2 \mathrm{~m}$ en dirección $\mathrm{N}-\mathrm{S}$, con la particularidad que en el extremo N-W del área se encuentra el pozo ciego (se describe más abajo en el punto 3), siendo tangente la circunferencia del pozo a la cara norte del área de intervención. Hacia el este de la superficie hay un árbol a unos $2 \mathrm{~m}$ aproximadamente. En la cara norte del área se encuentra un muro de $20 \mathrm{~cm}$ de espesor que se desarrolla en toda la longitud del área (los 2,50 $\mathrm{m}$ dirección E-W). En este sector se recuperaron 125 envases (enteros y fragmentados) de gres cerámico que conformaban la porción de contrapiso realizado con estas botellas de material cerámico cocido a alta temperatura y de máxima dureza (Figura 6). Desde la arqueología hay antecedentes de un hallazgo de similares características en la localidad de
Mercedes provincia de Buenos Aires (Schávelzon, 2009). En la ciudad de Rosario resulta ser novedoso y es el primer hallazgo en su tipo donde se utiliza este sistema constructivo de piso y/o contrapiso con envases de gres. Estimamos que se usaron estas botellas porque habían sido descartadas como envase de las cervecerías preexistentes en el actual predio desde 1870 (Volpe, 2001). Pensando en el contrapiso, su utilización resulta en una opción técnica de muy bajo costo y de alta eficiencia estructural y térmica. Dada la capacidad portante del material y la forma de las botellas, el contrapiso soporta esfuerzos de carga importantes; se considera un recurso técnico de gran creatividad para resolver problemas de nivelación y definición de una base para solados sometidos a usos intensivos. Los envases recuperados en este sector del patio de la facultad son de diferentes tamaños y de tipo tanto sinusoidal como así también de tipo cilíndricas (Schávelzon, 1987, 2001).

3.- El pozo ciego con corona de ladrillo está ubicado en el extremo N-W del área donde se encuentra el contrapiso de gres cerámico. Tiene $83 \mathrm{~cm}$ de diámetro y una profundidad de $3,35 \mathrm{~m}$. (Figura 7). Claramente es una infraestructura sanitaria para el desecho y tratamiento de líquidos cloacales de desperdicio. Es notoria la existencia de varias conexiones de cañerías provenientes de diversos puntos del actual patio que, a su vez, desaguan en el interior a diferentes alturas. Cumple con todas las condiciones técnicas de ese equipamiento, con una zona superior resuelta con una cúpula vaída de ladrillos y su tambor de apoyo que ocupa la porción superior del cilindro completo. La zona inferior está realizada como ahuecamiento del suelo natural, sin más terminación y material que la tierra. El pozo podría haber sido parte de las instalaciones de todo tipo de uso y ocupación del solar, tanto

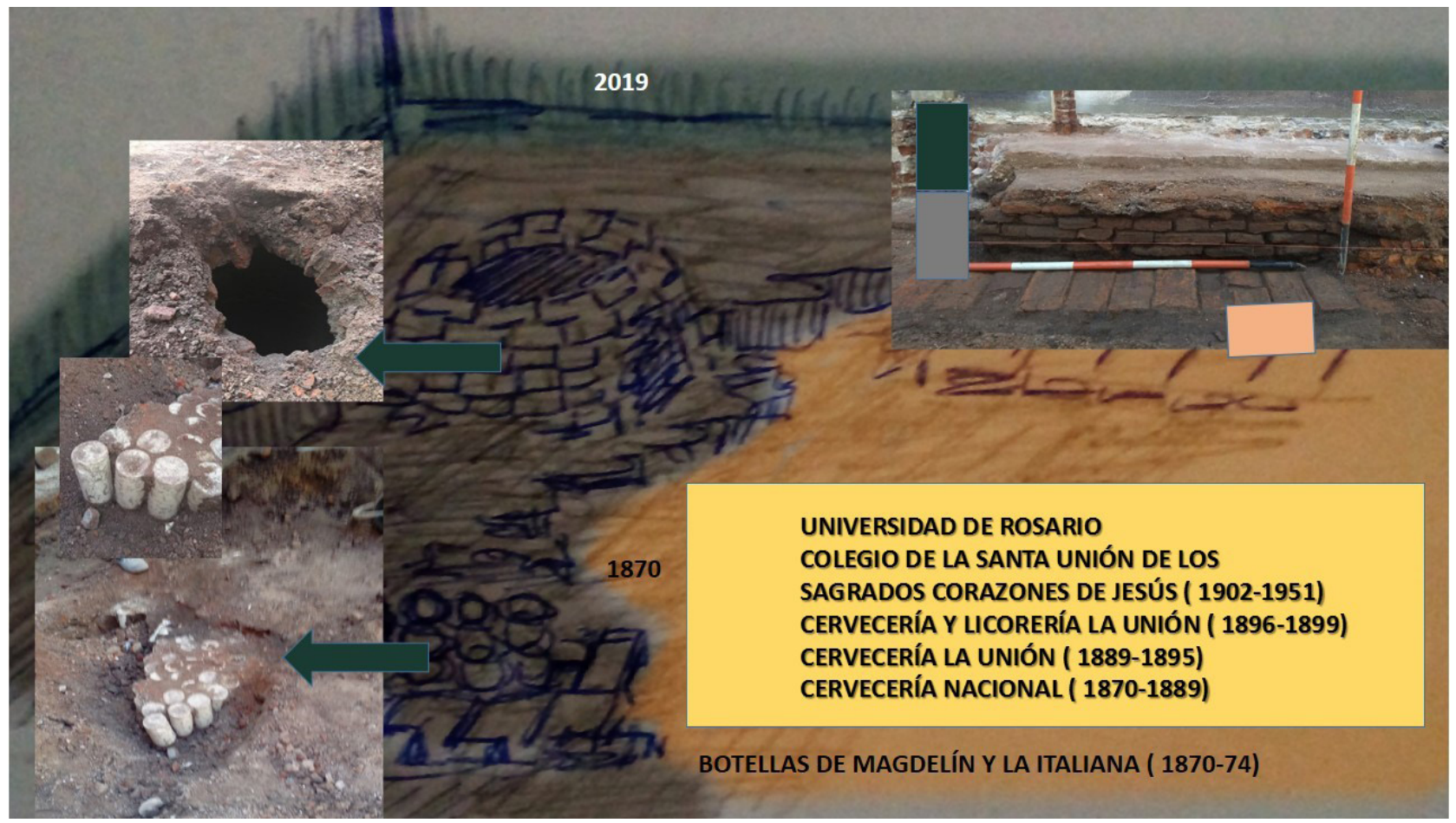

Figura 4. Esquema de los distintos momentos de ocupación del predio (Gentileza Soccorso Volpe, 2019). 


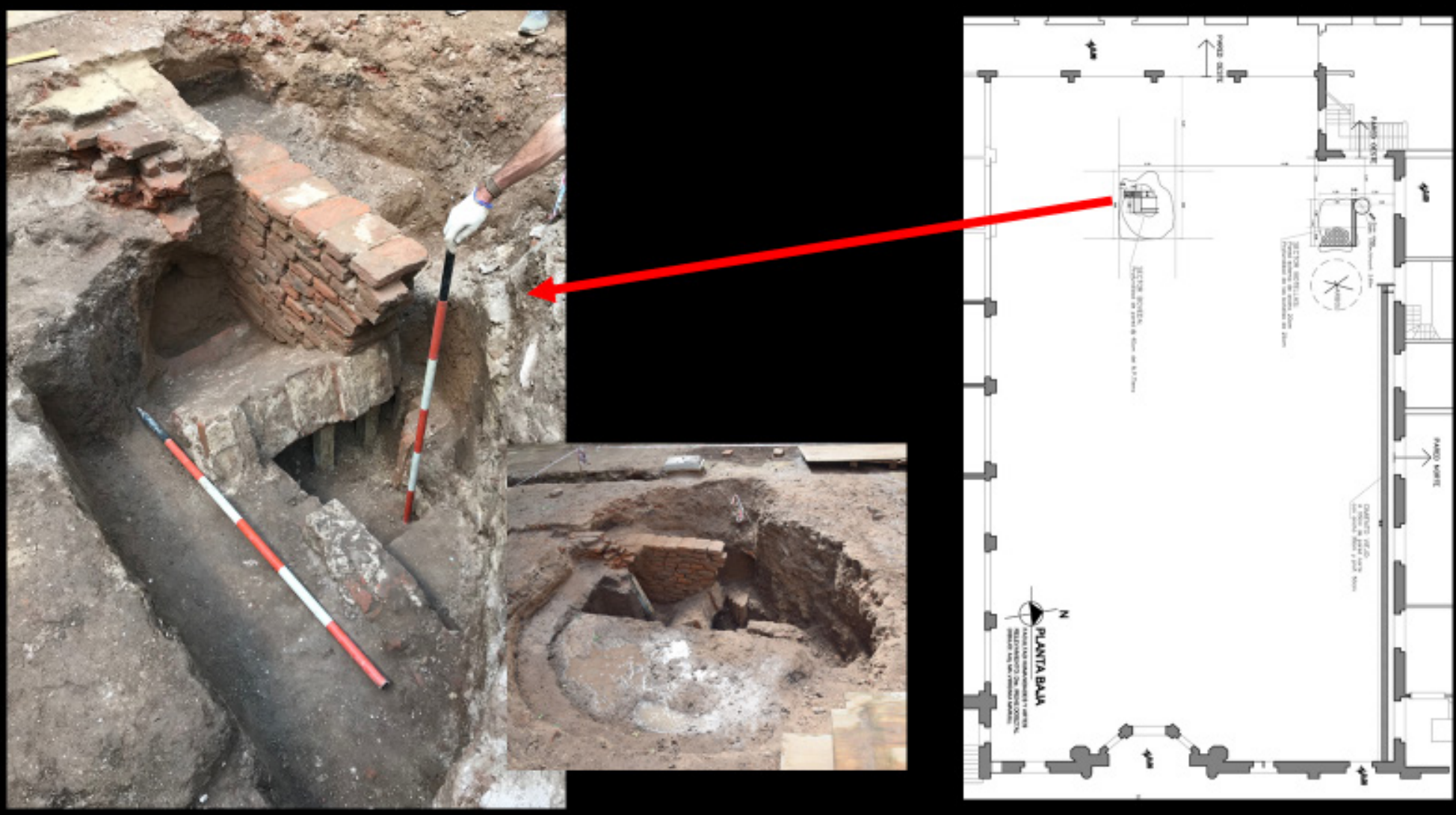

Figura 5. Bóveda y otras estructuras encontradas en el sector debajo del mástil.

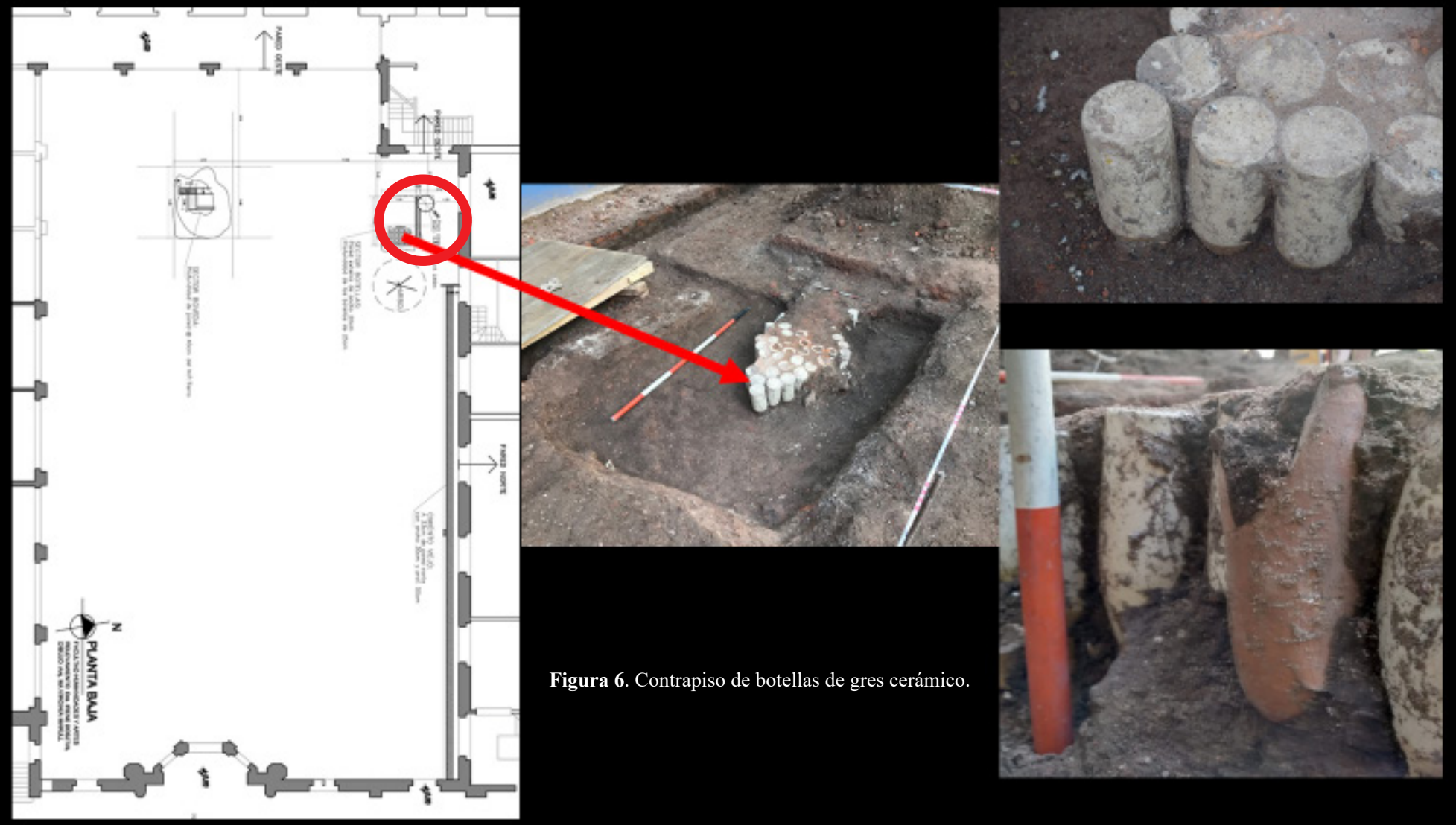



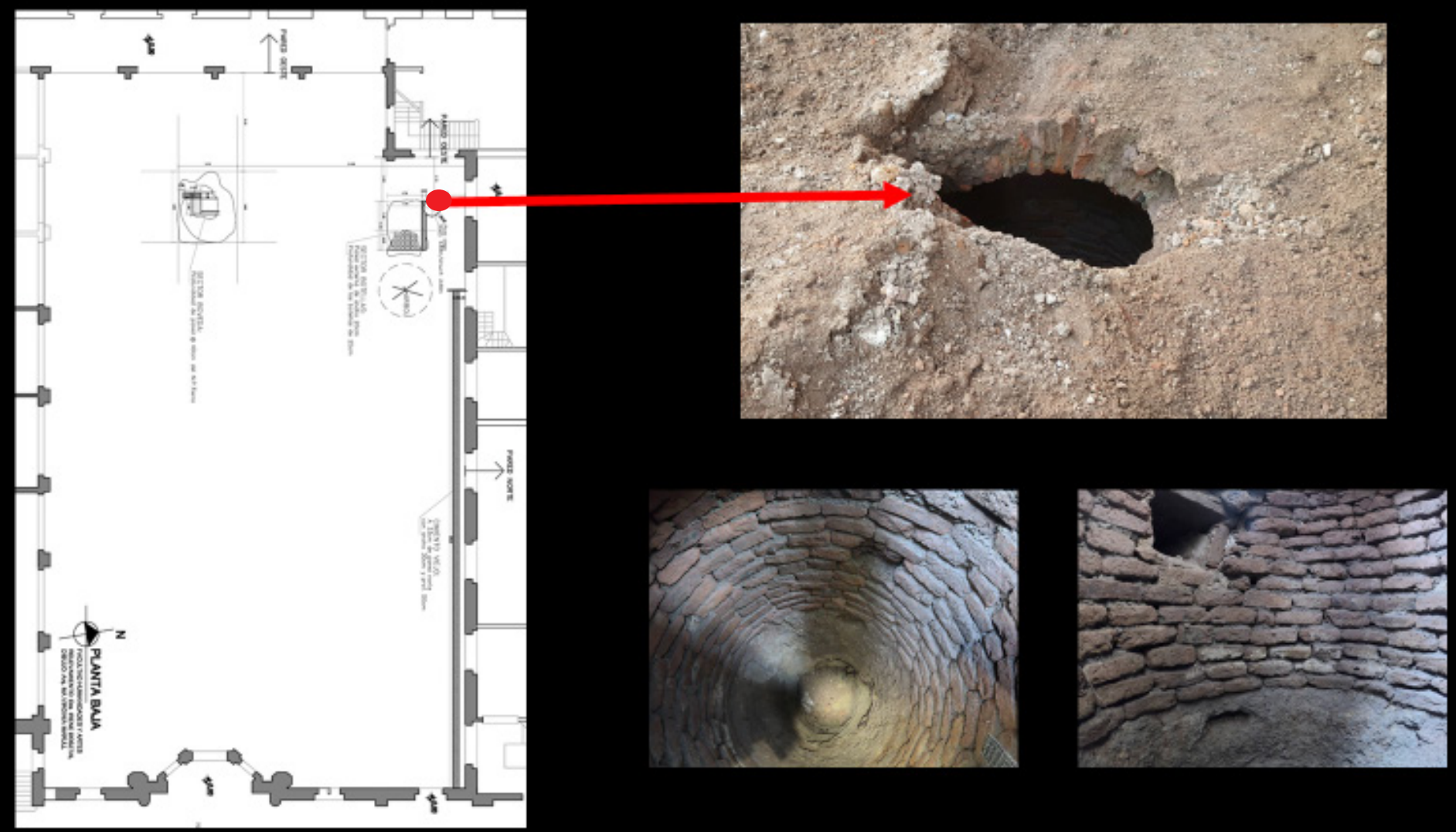

Figura 7. Pozo ciego con corona de ladrillos.
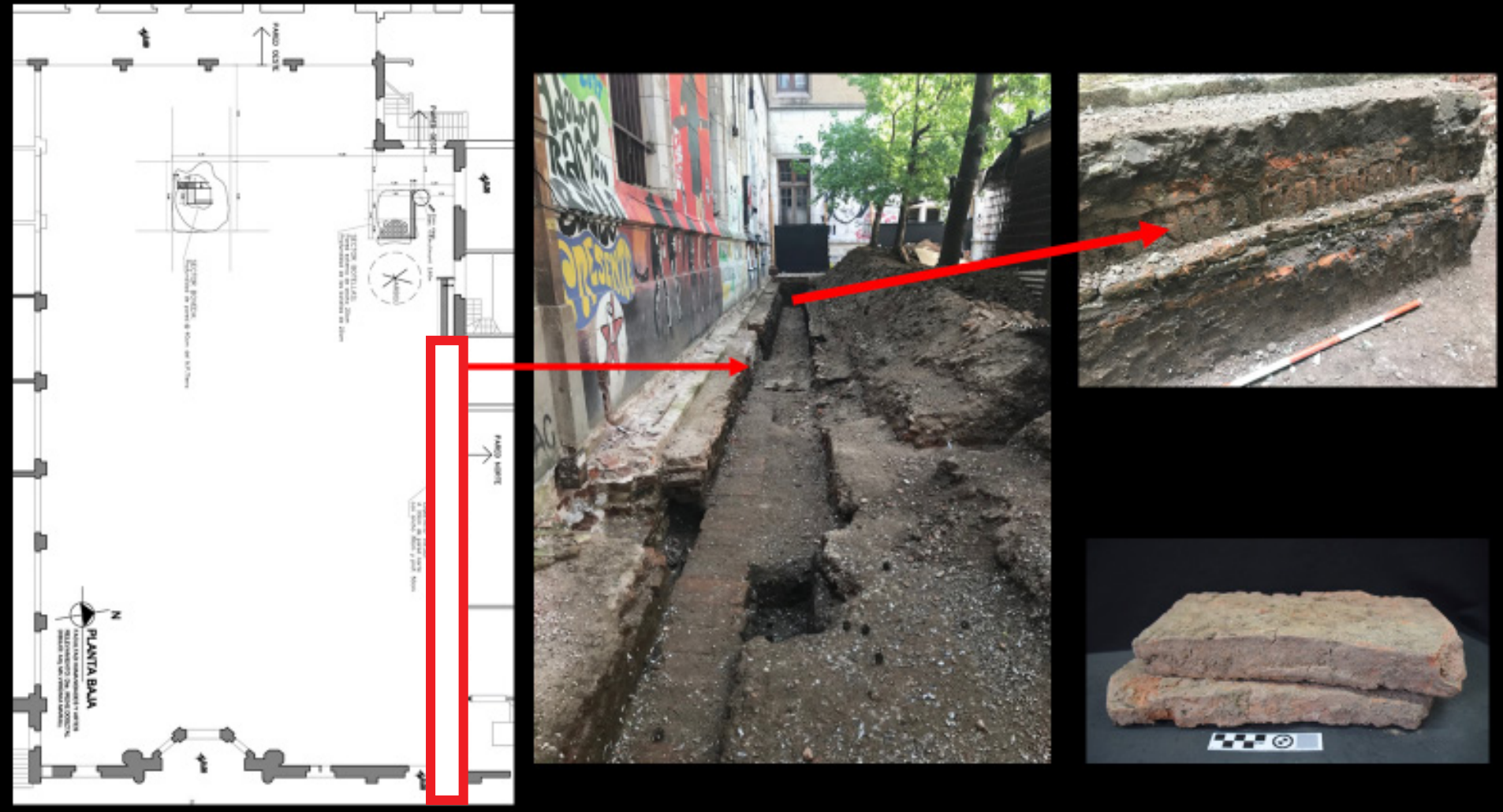

Figura 8. Cimientos en el sector N-W del patio hacia calle Santa Fe 
de las cervecerías sucesivas o del colegio.

4.- En correspondencia con la pared norte del patio (y en casi la totalidad de su longitud E-W) y a $33 \mathrm{~cm}$ de la pared, se relevó la existencia de un antiguo cimiento de $30 \mathrm{~cm}$ de espesor por $50 \mathrm{~cm}$ de profundidad, la longitud determinada del cimiento es de $25.22 \mathrm{~m}$. Estas estructuras de muros corresponden a momentos temporales distintos (Figura 8), se hallaron en el perímetro del patio y en su totalidad están realizadas con mampostería ladrillera y morteros como ligantes en juntas, claramente forman parte de diferentes pisos de ocupación de edificios pertenecientes a las distintas cervecerías instaladas en el predio a partir de 1870 .

\section{El aporte de los documentos}

A través de las investigaciones en archivos se ha podido determinar el solar perteneciente hoy a la Facultad fue adquirido por Enrique Monetta a Julián Bustinza en 1869. Este dato fue relevado en el Archivo Torriglia de nuestra facultad (Figura 9), donde se halló un plano con las delimitaciones de los solares y libros referenciales de escrituras. A partir de esta fecha se pudo reconstruir cuáles fueron las ocupaciones sucesivas del terreno hasta que la orden eclesiástica lo adquirió (Figuras 10 y 11). En Catastro Municipal, específicamente en Obras Particulares, se consiguió el plano completo del edificio del colegio concerniente a las obras de salubridad, firmado por el constructor Pedro
Giudice. Se localizó una serie de fotografías que muestran el estado del patio durante diferentes momentos, algunas de las cuales están en el informe 2018 (ver Tambuirini et al., 2019) y otras, relevadas con posterioridad, son publicadas en el presente informe (ver Anexo: Serie de fotografías de la FHyA y su patio a través del tiempo, más abajo).

Otro aporte realizado por Agustina Prieto (Museo de la Ciudad de Rosario, 2019) da cuenta de una noticia publicada en el diario "El Municipio" el 6 de octubre de 1892, donde se hace referencia a la "Cervecería La Unión" ubicada en la calle Entre Ríos 752. En la nota periodística se menciona a los propietarios Giannasi y Passerini, y destaca la importancia de esta cervecería para la ciudad:

“.. el establecimiento estaba dividido en varias secciones, (...), una para la fabricación de cerveza, otra para el hielo, otra para la soda y gaseosa, etc. (...). Hay después dos grandes calderas para la cerveza que tienen una capacidad de 6000 litros, que es la cantidad que se fabrica diariamente y luego viene la maquina ultimo sistema perfeccionado, para la fabricación del hielo. El laboratorio, con los necesarios aparatos frigorificos, y el depósito para la fermentación, son dos vastos salones que reúnen todas las comodidades necesarias y en donde se encuentran instalados los aparatos relativos más modernos. La maquinaria para la fabricación de la soday de la gaseosa no desmerece en nada todo lo demás. Viene luego el vasto local que sirve de depósito y en donde se

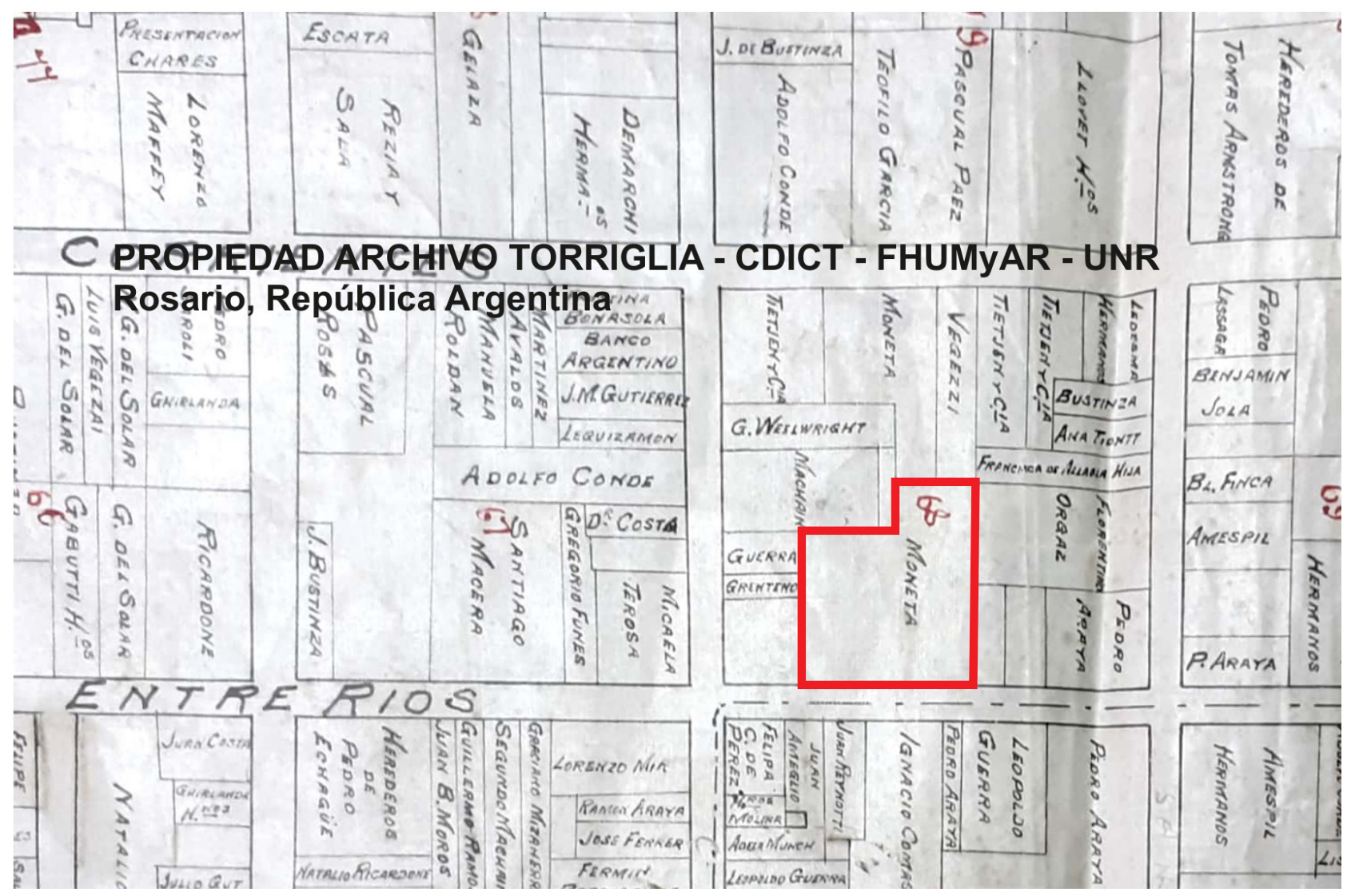

Figura 9. Plano de la FHyA. Gentileza Archivo Torriglia. 


\section{Por Jorge di Fiore}

\begin{tabular}{|c|c|c|c|}
\hline \multirow[t]{6}{*}{$\begin{array}{l}\text { entre Rios } 170 \text { entre Cordoba y Santa Fe. } \\
\text { actual } 752\end{array}$} & 1870.77 & Cerveceria Nacional & Carlos Bagans-Epitanio Moneta \\
\hline & 1877.83 & Cerveceria Nacional & Remate Judicial-22 abril 1877 \\
\hline & $1883-89$ & Cerveceria Nacional & Pedro Gerhardts \\
\hline & 1889.95 & Cerveceria Union & Wildermuth,Stocker y Navarro \\
\hline & 1895.96 & Cerveceria, Licoreria Unión & Gianasi y Passerini \\
\hline & $1896-99$ & Cerveceria Licoreria Unión & Wildermuth. Stocker $v$ Navarro \\
\hline \multirow[t]{8}{*}{ Entre Rios y Catamarca } & $1858-60$ & Cerveceria Nueva & Federico Pommerenke \\
\hline & 1860.66 & Cerveceria Nueva & Gustavo Blein \\
\hline & $1866-74$ & Cerveceria Nueva & Federico A. Engle-F.Magdelin 1870 \\
\hline & $1874-84$ & Cerveceria Alemana & Fernando Magdelin \\
\hline & 1884.86 & Cerveceria Alemana & Juan M. Ortiz \\
\hline & 1886.93 & Cerveceria Alemana & Carl Schlaū y Federico Strasser \\
\hline & $1893-07$ & Cerveceria Alemana & Carl Schlaul \\
\hline & 1907 & Cerveceria Alemana & Sucesión de Carl Schlaù \\
\hline \multirow[t]{5}{*}{ Entre Rios 1123} & 1876.93 & Cerveceria Santa Rosa & Costa, Falcone y Cia. \\
\hline & $1893-96$ & Cerveceria Universal & Costa, Falcone, Strasser (*) \\
\hline & 1896.99 & Cerveceria Strasser & Federico Strasser $(* *)$ \\
\hline & 1900.14 & Cerveceria Germania & Wiedenbrilg Hermanos (***) \\
\hline & 1914 & Cerveceria Germania & Cambia por Destilerias El Globo \\
\hline
\end{tabular}

(*) SA Presidente César Falcone 1896 a 1897

(**) Presidente Luisa Sajoux 1897 a 1899

(****) Destileros deade 1886

Figura 10. Gráfico extraído de http://www.botellasdecerveza.com.ar/ donde puede verse la sucesiva ocupación de empresas de cervecería en el solar desde 1870 a 1899 (acceso, 20 de julio, 2020).
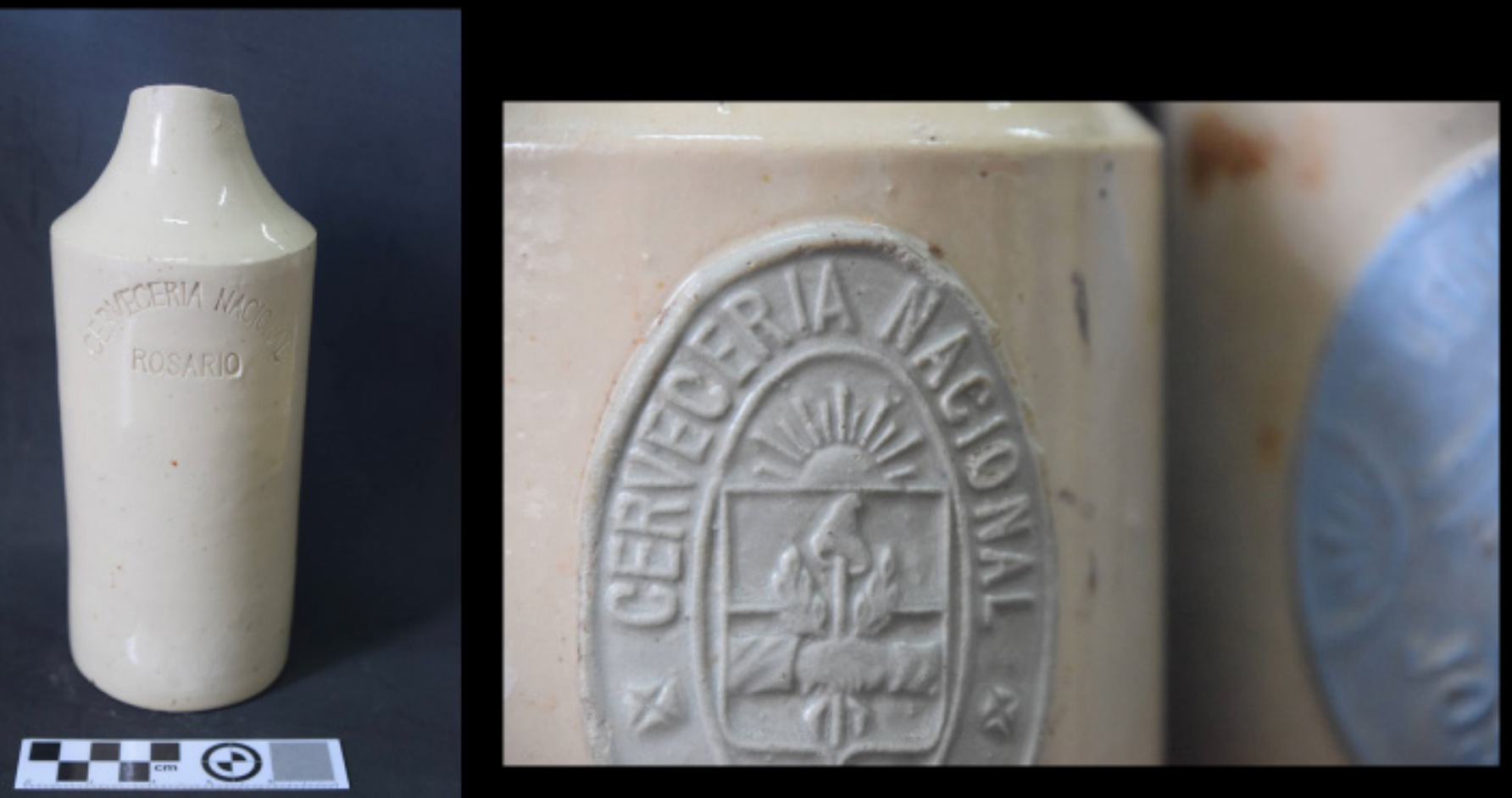

Figura 11. Envases recuperados con el sello Cervecería Nacional. 
procede a embotellar la cerveza, sirviéndose a ese objeto de máquinas sistema Enzinger. El establecimiento, que cuenta con 6 carros para el reparto, funciona desde hace 7 años, pero últimamente se introdujeron en él importantes mejoras que, como hemos dicho, lo ponen a la par de los mejores del país. La casa tiene además un depósito de licores de las principales fabricas del país y extranjeras y cuenta con una sucursal en Villa Casilda (...)

\section{Resultados alcanzados}

Las diversas estructuras encontradas en el patio del edificio, en su totalidad realizadas con mampostería ladrillera y morteros como ligantes en juntas, han estado perdiendo su capacidad estructural desde su exposición al aire. Este proceso solo puede evitarse por medio de su inmediata consolidación o bien volviendo a cubrirlas y contenerlas con materiales neutros que ayuden a resolver su capacidad portante. Mientras las variaciones de temperatura y precipitaciones sigan afectándolas, las estructuras tendrán inevitablemente un deterioro enorme que terminará en su colapso. En pos de su preservación, debería volverse a su estado previo a la excavación.

"Un hecho fundamental en la conservación de sitios arqueológicos es que la solución casi ideal de preservación consiste en volver a enterrar los restos arqueológicos expuestos. Los restos arqueológicos de fácil deterioro sobreviven mayor tiempo en el ambiente constante proporcionado por la tierra, arena y agua circundantes, que al ser sometidos a la exposición atmosférica. Por lo tanto, en lo que se refiere a conservación, mientras un sitio permanezca por más tiempo enterrado o sin excavar, mejor será su preservación." (Stanley Price, 1984, p. 87).

\section{"La experiencia obtenida al preservar y presentar sitios ha demostrado que los esfuerzos de estabilización y restauración nunca pueden ser medidas permanentes en sí mismas ya que el deterioro es un proceso dinámico sin fin. En los sitios expuestos, se requiere de una gran dedicación, no tanto con el propósito de mantener sin cambios el medio sino de mitigar los efectos del tiempo. Al darse cuenta de esto, se debe aceptar que el manteni- miento es una parte esencial de la preservación. " (Stan- ley Price, 1984, p. 94).}

La exposición in situ de los constructivos, hizo necesario evaluar la disponibilidad de los materiales correctos, así como el tiempo que se tardará para realizar las protecciones. Teniendo en cuenta esto y las consultas realizadas, así como la bibliografía especializada, tras consultar la disponibilidad con las autoridades de la universidad y facultad, se optó por cubrir los constructivos. Para tapar los sectores excavados se terminó de retirar las botellas de gres que aún quedaban, rellenar el pozo ciego por cuestiones de seguridad ya que el patio es un lugar de alto tránsito diario y en el sector de la bóveda se aplicó un recubrimiento con un geotextil. En este caso, es un recubrimiento de media sombra gruesa que envuelve las estructuras. Se colocó una capa de arena y sedimento antes del recubrimiento final de la obra del contrapiso (Figuras 12 y 13). El análisis y la interpretación de los datos recabados serán informados y publicados a medida que se continúe con las investigaciones.
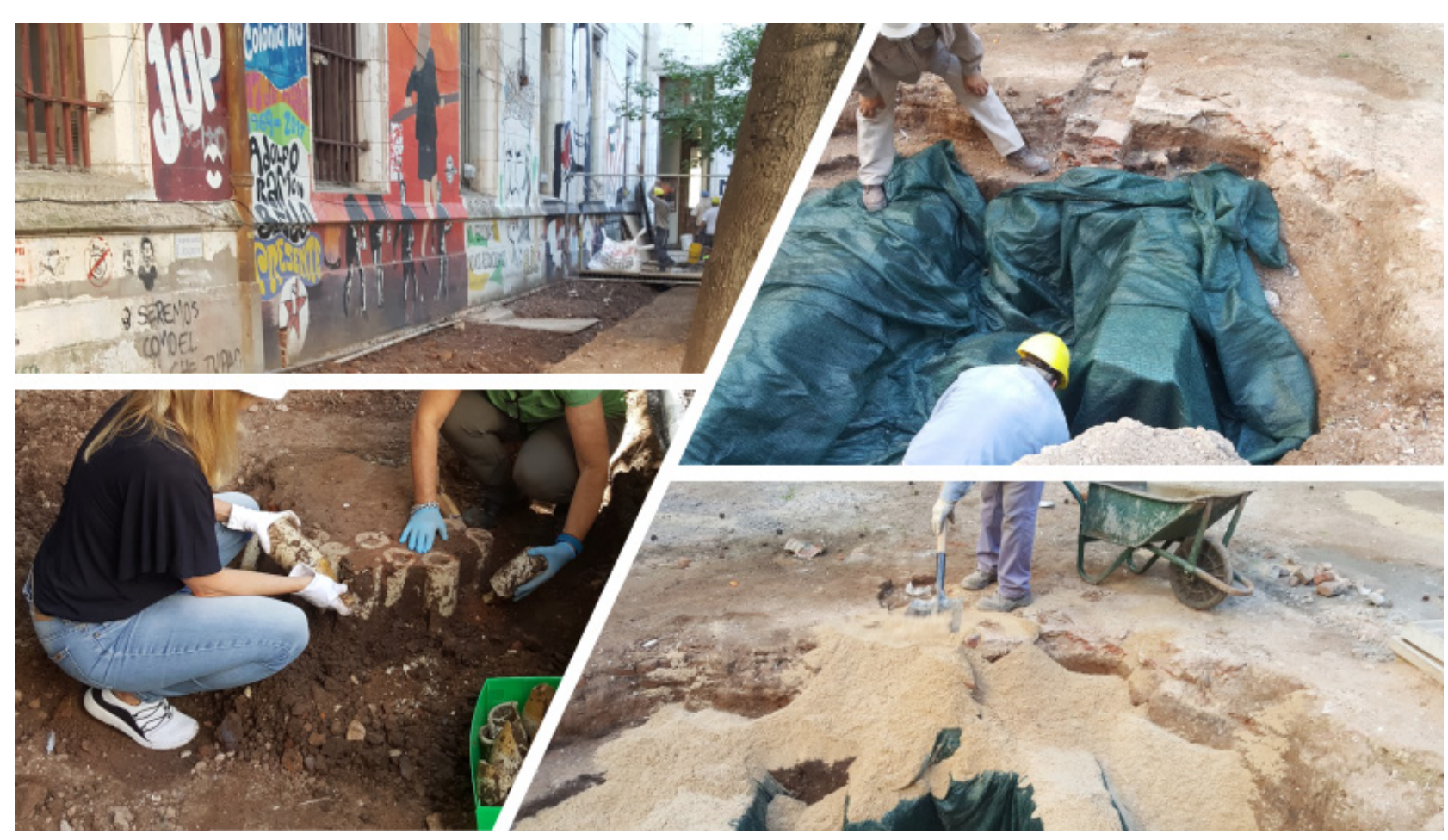

Figura 12. Retiro de botellas de gres que conformaban el contrapiso. Relleno y recubrimiento con el geotextil del sector bóveda, 2019. 

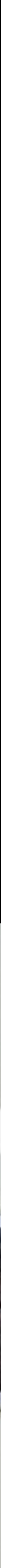

Figura 14. Muestra fotográfica en el VIII Simposio de Arqueología Histórica, los días 28 y 29 de noviembre 2019 , Rosario. 


\section{Consideraciones finales}

Esta pesquisa constituye un enfoque novedoso en tanto hasta el momento se desconocía la potencialidad material e histórica previa al establecimiento del Colegio Religioso Santa Unión de los Sagrados Corazones, construido entre 1902 y 1903. La investigación arqueológica, catastral e histórica reveló la existencia de establecimientos cerveceros desde 1870 en el actual predio de nuestra facultad. La exploración se llevó a cabo combinando los aportes de la arqueología de rescate, junto con la investigación bibliográfica y documental en diferentes archivos de la ciudad. De esta manera se contribuyó a profundizar el conocimiento acerca de esta emblemática casa de estudios, generando así información que conduce a la preservación y puesta en valor del edificio. Por lo tanto, las actividades realizadas por los docentes y estudiantes del Departamento de Arqueología representan tanto alcances científicos y académicos, como patrimoniales y educativos a nivel general (Figuras 14 y $15)$.

A un nivel académico-científico, se espera que el producto de este proceso resulte, a largo plazo, en un enriquecimiento sustancial de la visión existente de la FHyA, de su conformación y desarrollo como edificio histórico en la ciudad de Rosario. A un nivel más amplio, se espera que la investigación genere interés en la historia y patrimonio local, contribuyendo a su correcto manejo y gestión.
Figura 15. Muestra fotográfica expuesta en la Sala De Reuniones del Consejo Directivo en el sexto piso del nuevo edificio de la FHyA, diciembre 2019. Fotografías Javier García Cano.
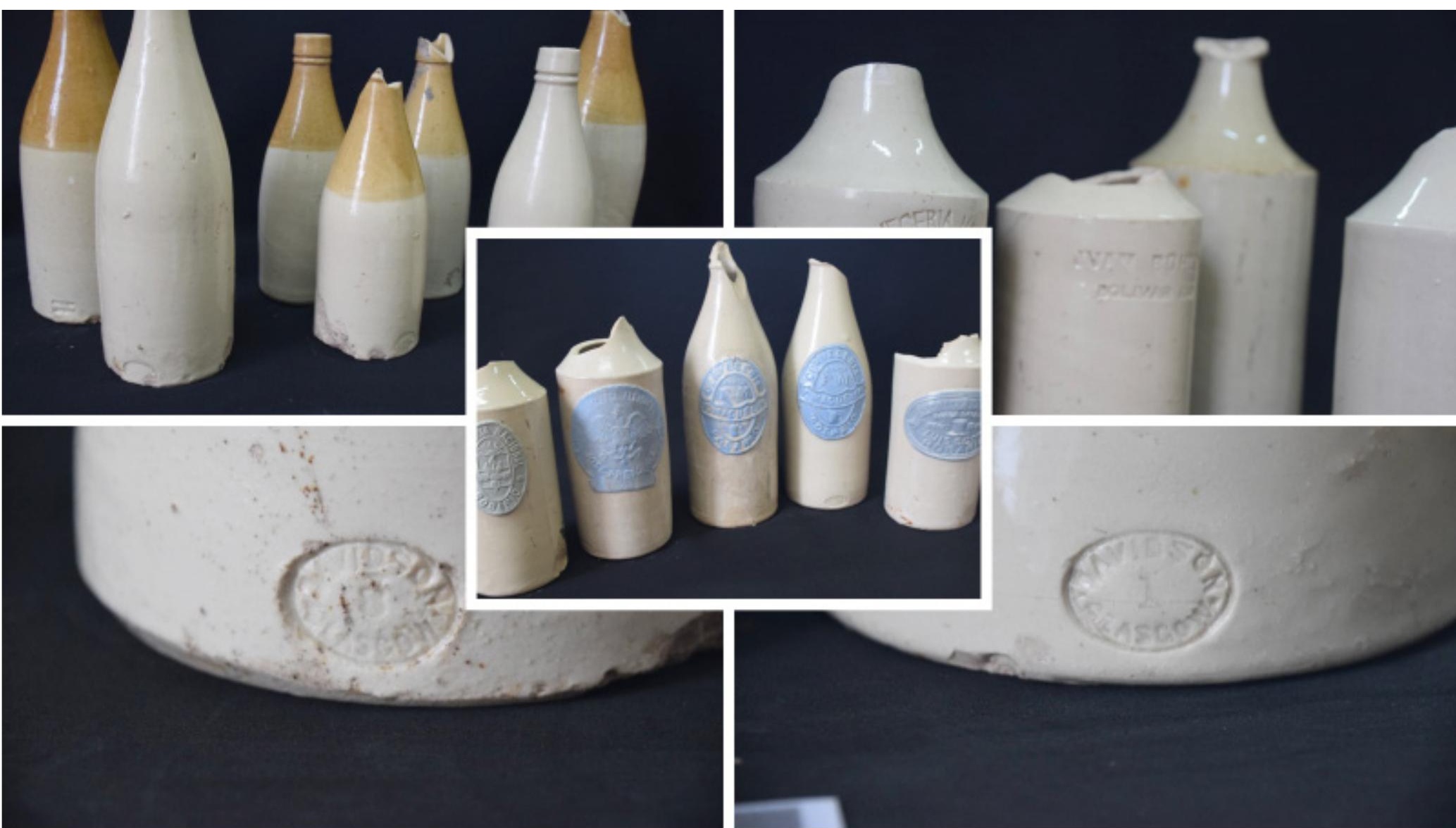
Anexo: Serie de fotografías de la Facultad de Humanidades y Artes y su patio a través del tiempo

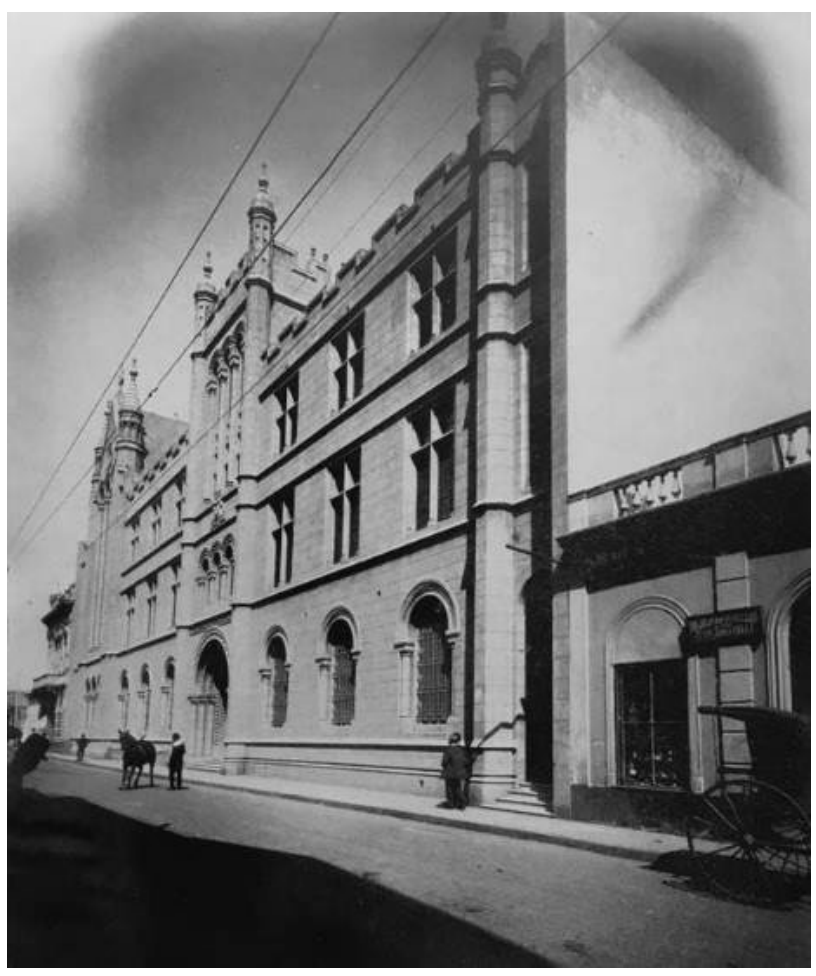

Figura 16. Fachada de la FHyA, 1905. Archivo digital Arquitecto Pablo Mercado.

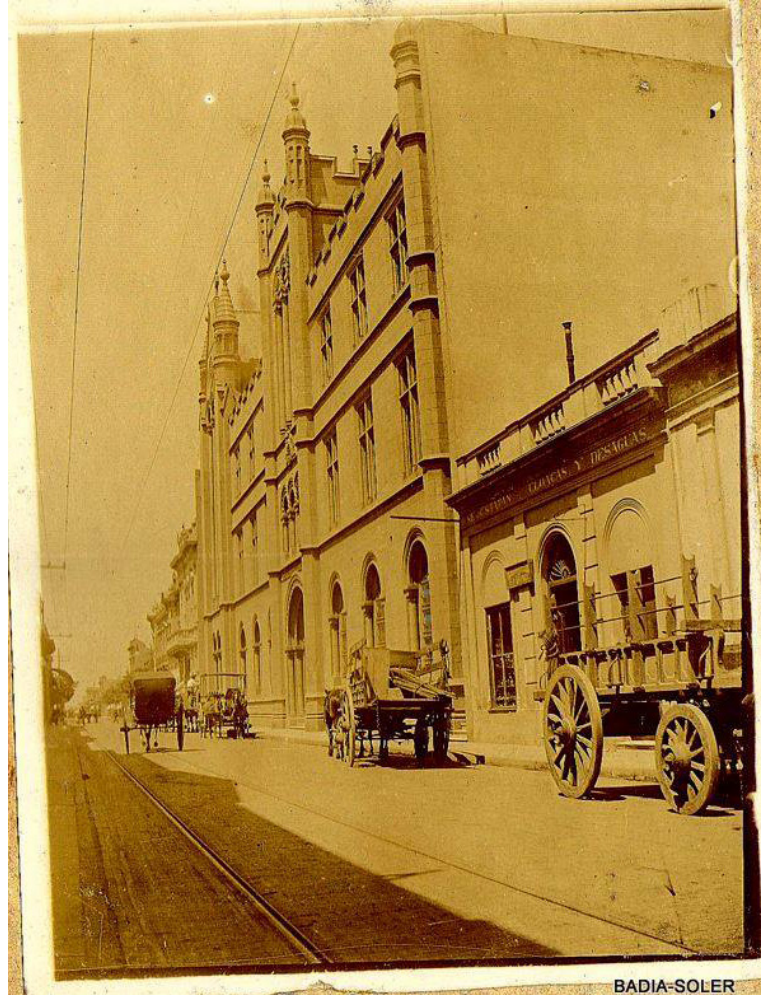

Figura 17. Fachada de la FHyA correspondiente a 1910, Fotografía de Alberto Soler.

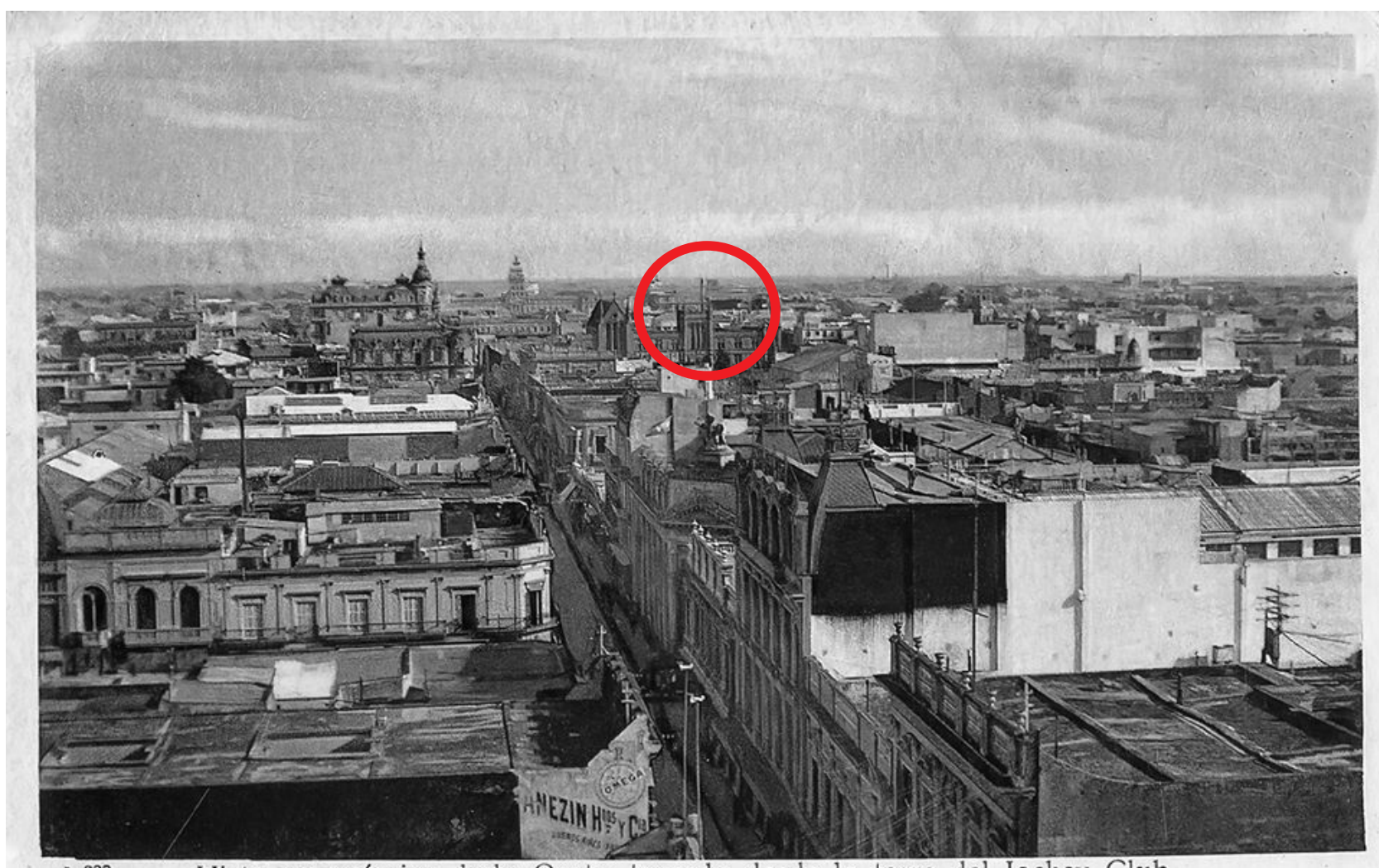

A 338 Vista panorámica, lado Oeste, tomada desde la torre del Jockey Club

Figura 18. Postal vista panorámica hacia el oeste, tomada desde el Jockey Club de Rosario, circa 1930 S/D 


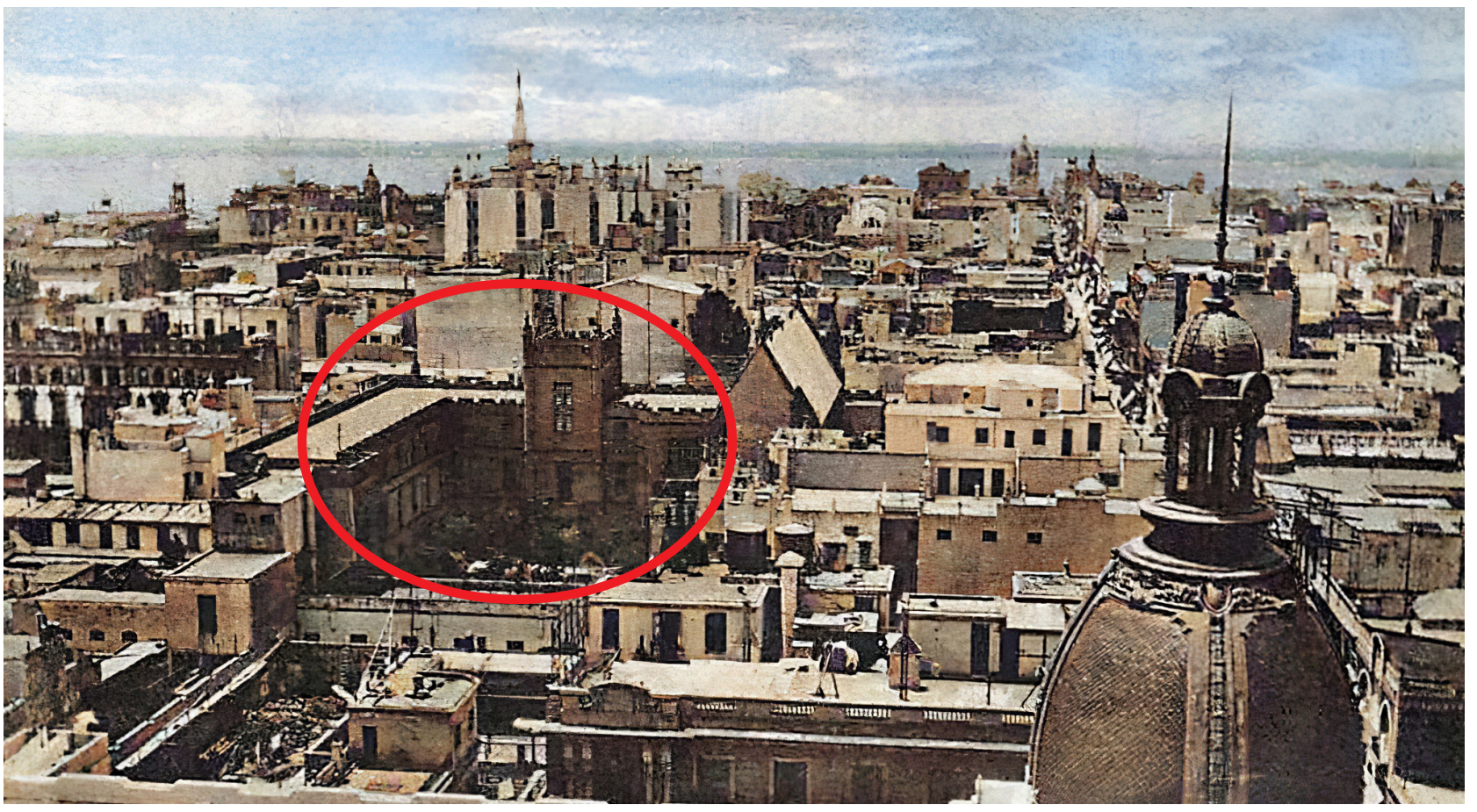

Figura 19. Vista parcial del patio de la FHyA 1930 S/D.

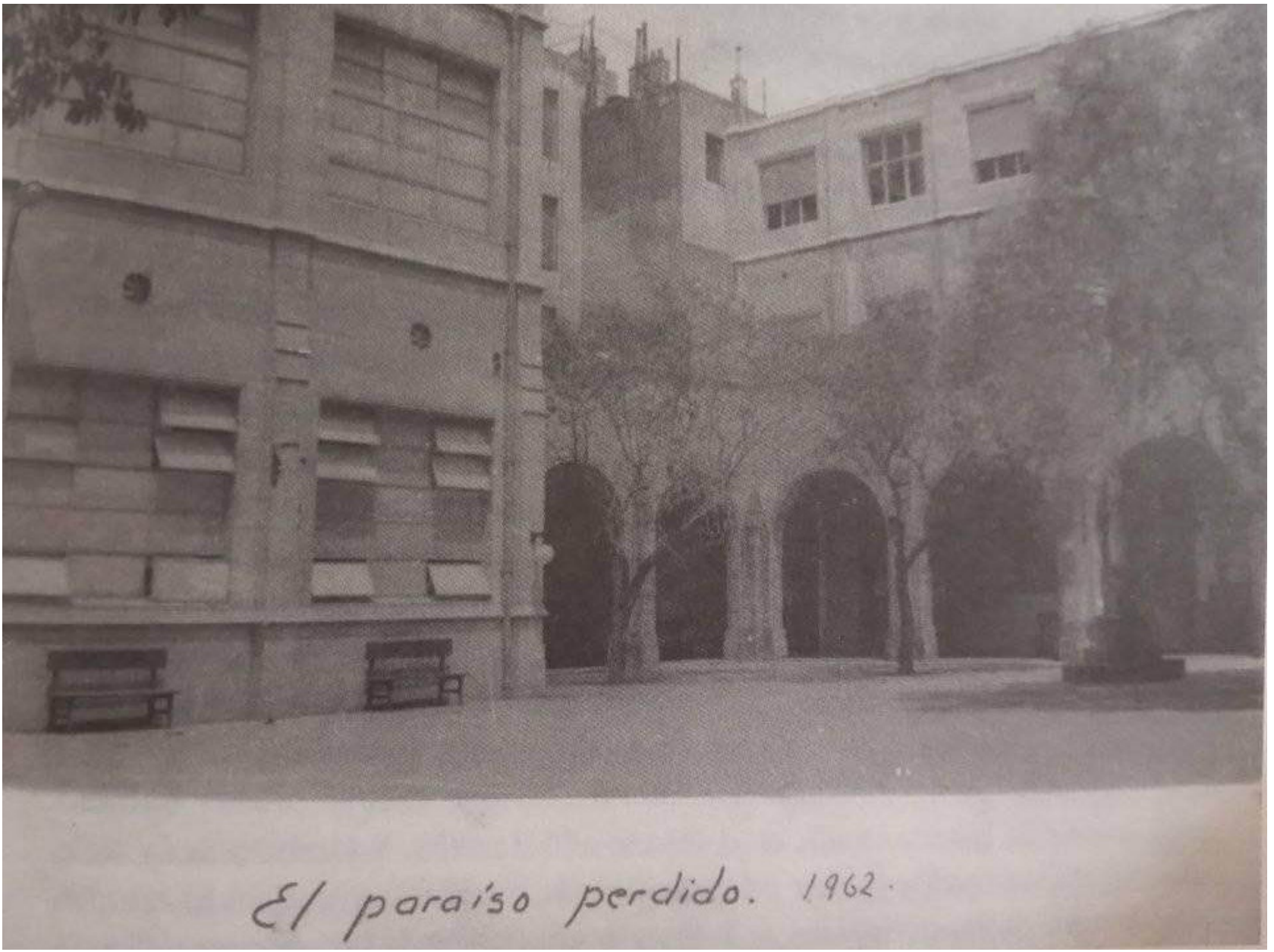

Figura 20. Fotografía del interior del patio, aun no se había construido la Escuela de Historia hoy demolida, 1962. 


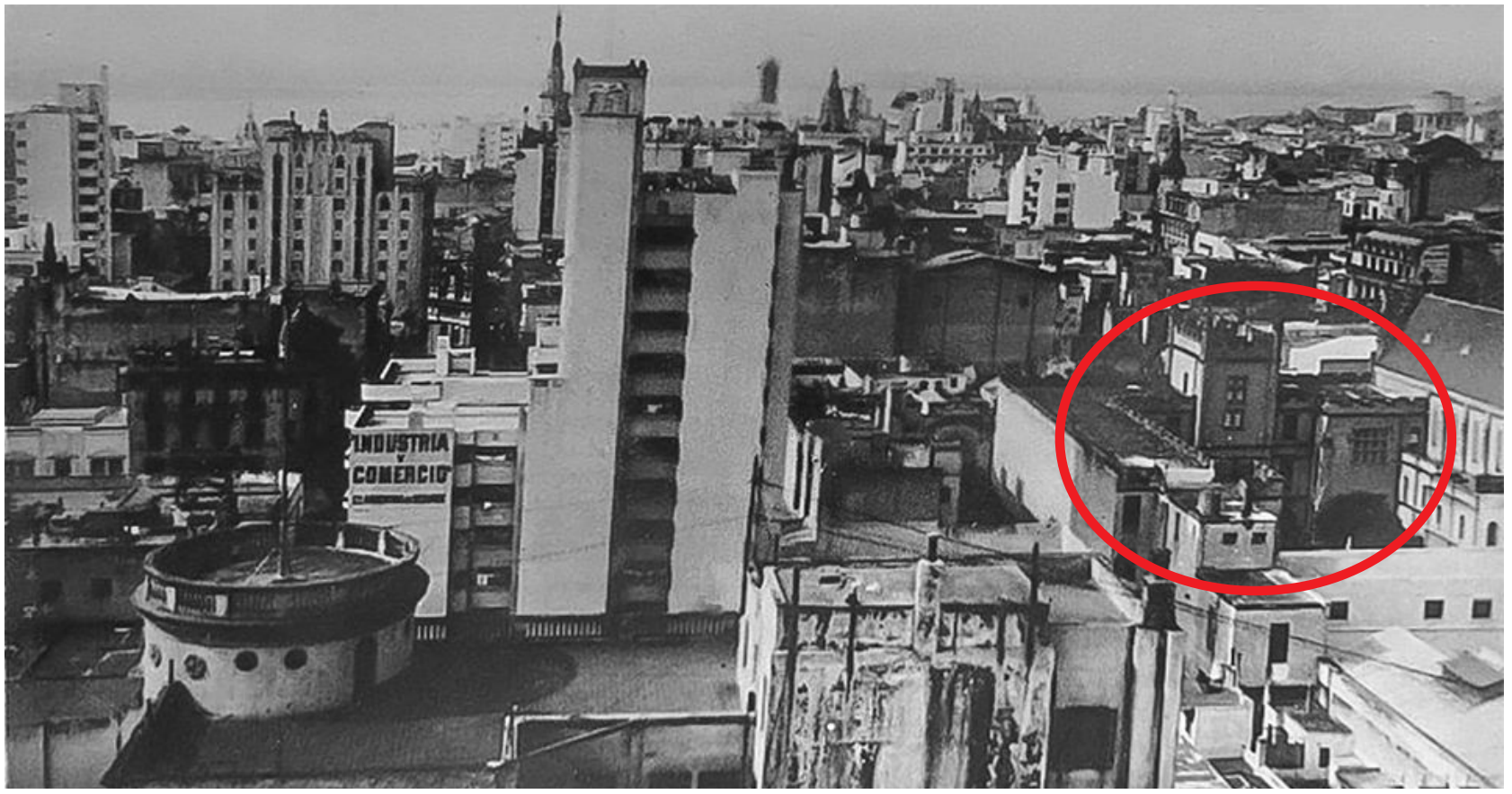

Figura 21. Postal de la ciudad de Rosario donde se observa el patio de la FHyA.
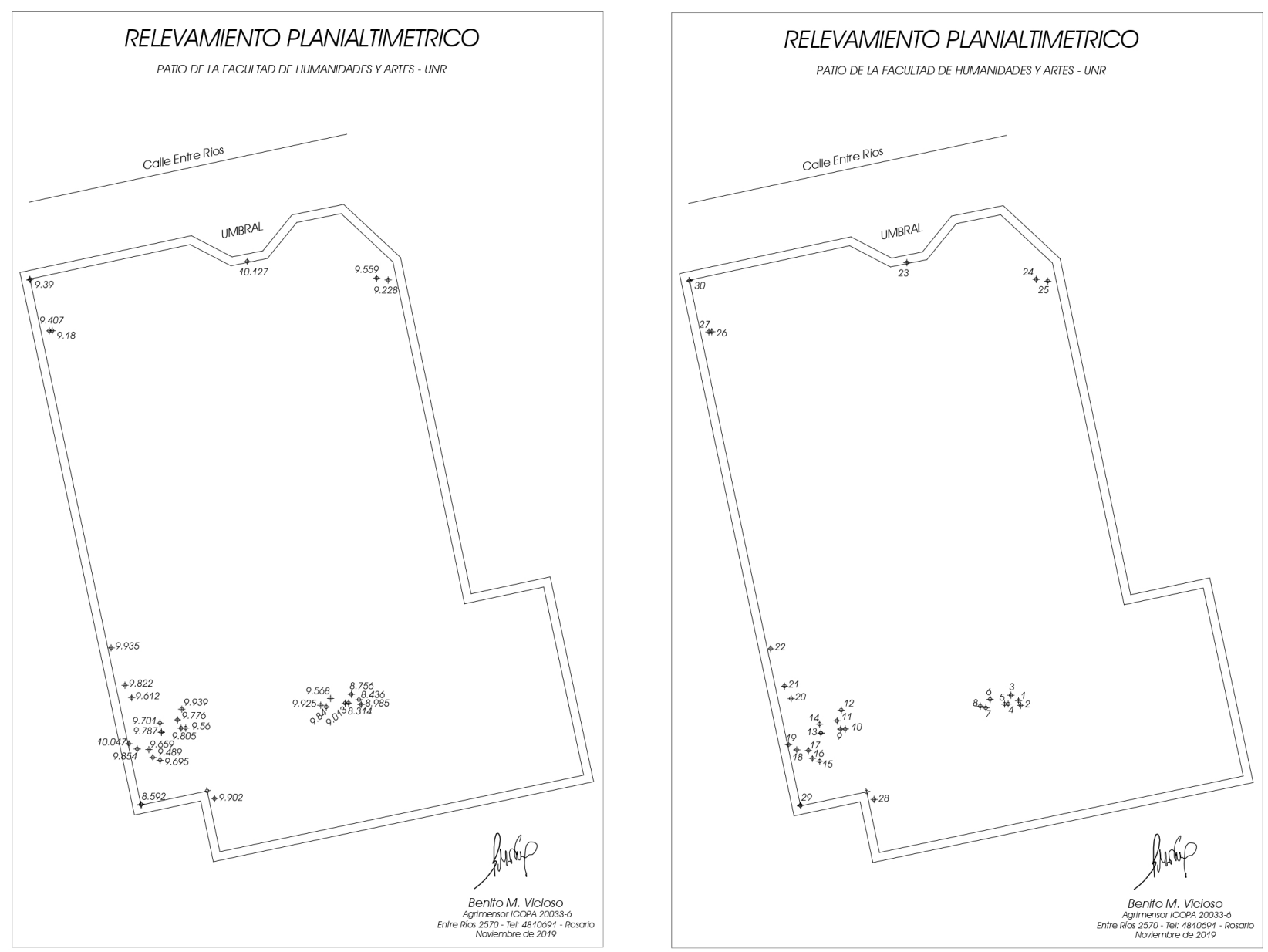

Figura 22. Puntos de relevamiento y cotas del patio de la FHyA realizado por Agrimensor Benito Vicioso 

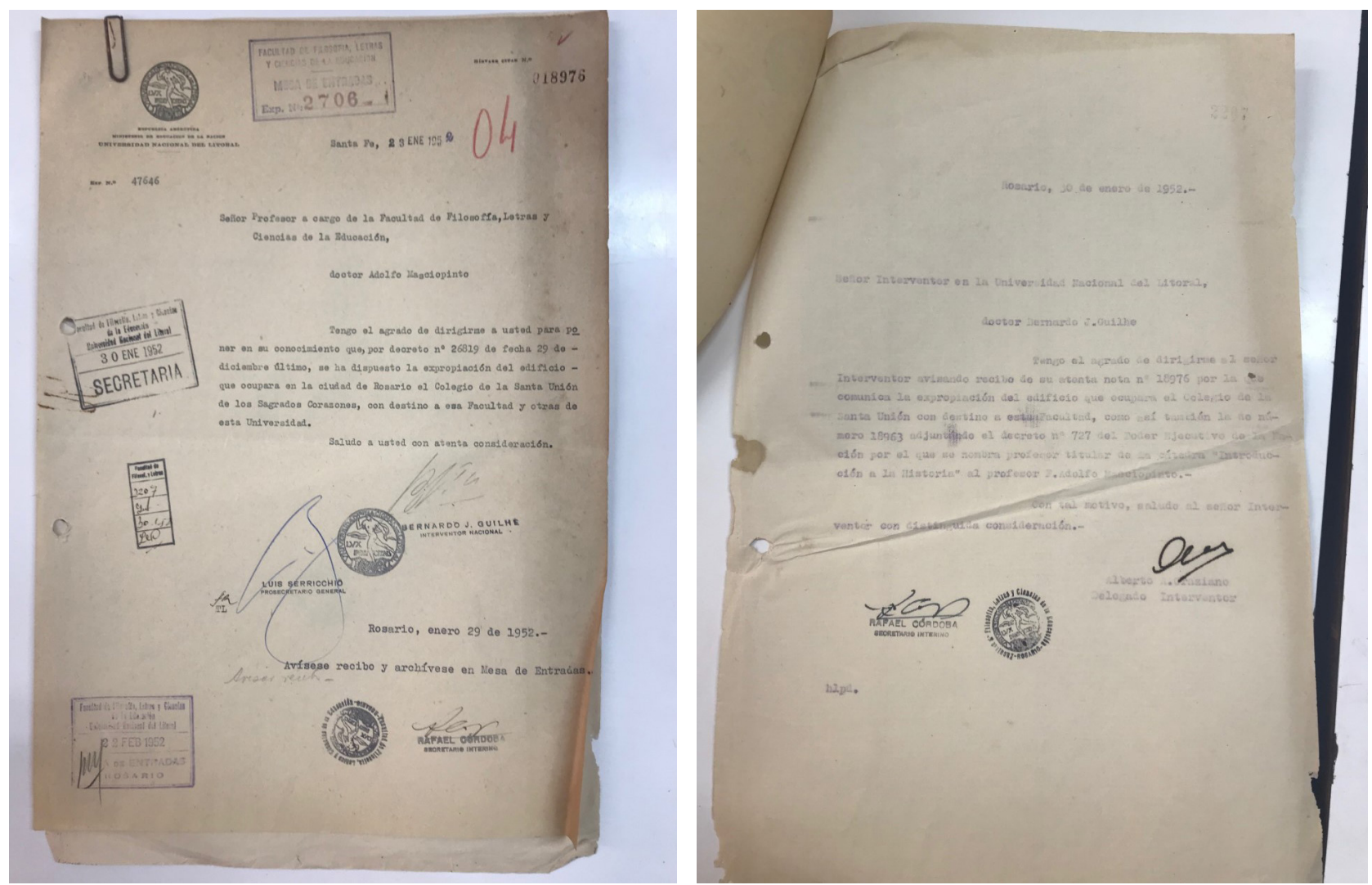

Figura 23. Fotografía de la nota de expropiación del edificio que ocupara el Colegio de la Santa Unión con destino a la FHyA, 30 de enero de 1952. (Gentileza Archivo y Programa de la Escuela de Historia).

Notas

1. "Se han realizado ya tres expediciones con alumnos al N.O. Estas expediciones, de las que las dos primeras se dedicaron a los interesantísimos yacimientos del Alamito, sirvieron también como escuela de Arqueología en el terreno. En nuestro medio la enseñanza práctica de arqueología no ha existido hasta ahora. Los alumnos de Historia de algunas Facultades realizaban viajes en periodos de vacaciones a fin de visitar, ruinas exploradas o semi exploradas. Nunca a realizar tareas en conjunto, en prácticas de campaña. En este sentido las tareas del Instituto han significado una innovación. A cada estudiante se le encomendó una tarea especifica (...) Los resultados irán surgiendo poco a poco" (González 1959, p. 6).

\section{Agradecimientos}

A las autoridades de la Facultad de Humanidades y Artes. A Sr. Enzo Navas, Virginia Chouhy, Alisa Ali León, Ailen Dainotta, Raúl Videla, Doroteo Florentino Isidro, Miguel Ledesma y Adam Escalada.

\section{Asesoramiento técnico}

Soccorso Volpe, Ana María Rocchietti, Agustina Prieto, Jorge Aramburu, Javier García Cano, Francisco Cadau, Manuel Fernández De Lucco y María Virginia, Marull.

\section{Bibliografía}

Camino, U. (2009). Rellenos Porteños. Revista de Arqueología Histórica Argentina y Latinoamericana, 3, 101-123.

González, A. (1959). Prólogo. Revista del Instituto de Antropología (Facultad de Filosofía y Letras, Universidad Nacional del Litoral), I, 5-7.

Schávelzon, D. (1987). Tipología de recipientes de gres cerámico para la arqueología histórica de Buenos Aires. Buenos Aires: Programa de Arqueología Urbana.

Schávelzon, D. (1992). La Arqueología Urbana en Argentina. Buenos Aires: Centro de Estudios de América Latina.

Schávelzon, D. (2001). Catálogo de cerámicas históricas de Buenos Aires (siglos XVI-XX) con notas sobre la región del Río de la Plata. CD. Buenos Aires: Fundación para la Investigación del Arte Argentina, Telefónica, FADU.

Schávelzon, D. (2009). La cerveza en el piso: arqueología de una cervecería en Mercedes (provincia de Buenos Aires), Anuario de Arqueología (UNR), 1, 29-36.

Schávelzon, D. (2018). Manual de Arqueología Urbana. Buenos Aires: CAU, FADU, UBA.

Stanley Price, N. (1984). La conservación en excavaciones arqueológicas. Roma: Iccrom.

Tamburini, D., Valentini, M., Algrain, M., Oliva, F., Bataggia, F., Scaglione, G., Abatangelo, F. \& Spinetta Cadirola, G. (2019). Arqueología en el patio de la Facultad de Humanidades y 
Artes. Informe de actividades temporada 2018. Anuario de Arqueología (UNR), 11, 143-152.

Valentini, M. \& Tamburini, D. (2019). Muestra fotográfica: El patio Cervecero. Presentada en el VIII Simposio de Arqueología Histórica. 28 y 29 de noviembre 2019.

Volpe, S. (2001). Vida cotidiana de Rosario (1870-1890). Introducción a la cerveza en Rosario. Revista el Vecino Rosario, 150, 23-35. 